\title{
Gebelerde İlk Trimester Plazma D Vitamini Düzeyleri ile Gestasyonel Diyabet Arasında İlişki Var mı?
}

\author{
Görker SEL ๑ $₫$, Selen SEYHAN BAYDAĞ ๑, Aykut BARUT ๑, Adile Yeşim AKDEMİR ๑, Ülkü ÖZMEN ๑, \\ Müge HARMA ๑), Mehmet İbrahim HARMA ๑
}

Zonguldak Bülent Ecevit Üniversitesi Tıp Fakültesi Hastanesi, Kadın Hastalıkları ve Doğum Anabilim Dalı, Zonguldak, Türkiye

Bu makaleye yapılacak atıf: Sel G, Seyhan Baydağ S, Barut A, Akdemir AY, Özmen Ü, Harma M, Harma Mİ. Gebelerde İlk Trimester Plazma D Vitamini Düzeyleri ile Gestasyonel Diyabet Arasında İlişki Var mı? Türk Diyab Obez 2020;1: 36-40.

\begin{abstract}
ÖZET
Amaç: Batı Karadeniz Bölgesinde, iki merkezde oral glukoz tarama testi (OGTT) uygulanmış gebelerde, gestasyonel diyabet (GDM) saptanan ve saptanmayan gruplar arasında ilk trimester plazma D vitamini seviyesinin ilişkisini araştırmaktır.

Gereç ve Yöntemler: 17.09.2014-15.01.2018 tarihleri arasında Bartın Devlet Hastanesi ve Zonguldak Bülent Ecevit Üniversitesi Tip Fakültesi Kadın Hastalıkları ve Doğum Anabilim Dalına başvuran 18-40 yaş arası, tekil gebeliği olan ve ilk trimesterde maternal plazmada D vitamini seviyesi bakılmış ve OGTT yapılmış 136 gebe çalışmaya dahil edildi, retrospektif olarak veriler tarandı. Çoğul gebelikler, gebelik öncesi diyabet gibi ek sistemik hastalığ bulunan, glukoz tarama testi yaptırmak istemeyen, ilk trimesterde D vitamini seviyesine bakılmamış ya da kan verme zamanında D vitamini takviyesi alan, zararlı madde kullanımı olan, çoğul gebeliği olan gebeler çalışmaya dahil edilmedi. GDM tanısı almış 52 gebe GDM grubu, diğer 84 gebe kontrol grubu olarak OGTT yapıldığı esnadaki yaş, gravide, parite, hemoglobin değeri ve vücut kütle indeksi (VKI) eşleşecek şekilde oluşturuldu.

Bulgular: Yaş, gravida, parite, hemoglobin, VKİ değerleri açısından her iki grup benzerdi ( $p>0,05)$. D vitamini seviyelerine bakıldığında ise GDM gelişen grupta, ilk trimesterdeki maternal D vitamini seviyesinin GDM gelişmemiş gruba göre anlamlı olarak düşük olduğu saptanmıştır $(\mathrm{p}=0,031)$.

Sonuç: $\mathrm{D}$ vitamininin diyabet patogenezinde rolü olduğu önceki çalışmalarda da gösterilmiştir. Ayrıca literatürdeki az sayıdaki çalışmada da saptandığı gibi bizim bölgesel çalışmamızda da GDM saptanan gebelerde D vitamini eksikliği göze çarpmaktadır. Batı Karadeniz Bölgesi’ni içeren bu çalışmamız daha kapsamlı prospektif çalışmalara yol gösterici nitelikte olacaktır.
\end{abstract}

Anahtar Sözcükler: Gestasyonel diabetes mellitus, D vitamini, Gebelik

\section{Is There a Relationship Between First Trimester Plasma Vitamin D Levels and Gestational Diabetes in Pregnant Women?}

\begin{abstract}
Aim: Carried out in pregnant women who had oral glucose tolerance test (OGTT) in two centers in the Western Black Sea Region, this study aims to investigate the relationship of the first trimester plasma vitamin D levels between the groups with and without gestational diabetes mellitus (GDM).

Material and Methods: Between the dates of 17.09.2014-15.01.2018 at Bartın State Hospital and Zonguldak Bülent Ecevit University Faculty of Medicine, Department of Obstetrics and Gynecology, 136 pregnant women aged between 18-40 with a single pregnancy who took OGTT and whose vitamin D levels in maternal plasma were examined in their first trimester were included in the study, and the collected data were reviewed retrospectively. Pregnant women who had additional systemic diseases such as pre-pregnancy diabetes, or those with multiple pregnancies, or the ones who did not want to have a glucose screening test, who had not their vitamin $\mathrm{D}$ level tested in the first trimester, who were taking vitamin D supplements at the time of admission were not included in the study. The GDM Group of 52 pregnant women who were diagnosed with GDM were matched with the other 84 pregnant women who formed the control group according to the age, gravida, parity, hemoglobin value and body mass index (BMI) at the time of the OGTT test.
\end{abstract}

ORCID: Görker Sel / 0000-0001-8653-5687, Selen Seyhan Baydağ / 0000-0003-1478-4355, Aykut Barut / 0000-0002-8574-5065, Adile Yeşim Akdemir / 0000-0002-6454-6120, Ülkü Özmen / 0000-0001-7979-4015, Müge Harma / 0000-0002-4327-674X, Mehmet İbrahim Harma / 0000-0002-9734-5253 
Results: Both groups were similar in terms of age, gravida, parity, hemoglobin and BMI values ( $\mathrm{p}>0.05)$. Considering vitamin D levels, it was found that the level of maternal vitamin D in the first trimester was significantly lower in the group that developed GDM when compared to the group that did not develop GDM ( $\mathrm{p}=0.031)$.

Conclusion: Vitamin D has also been shown to play a role in the pathogenesis of diabetes. In addition, as seen in the few previous studies in the literature, vitamin D deficiency in pregnant women with GDM is found in our regional study, as well. This study, which includes the Western Black Sea Region, will guide more comprehensive prospective studies.

Key Words: Gestational diabetes mellitus, Vitamin D, Pregnancy

\section{GİRIŞ}

D vitamini "Güneş Vitamini” olarak adlandırılır, çünkü güneşten gelen Ultra Violet B (UVB) 1şınları ile cilt D vitamini doğal olarak üretilir (1). İki ana $\mathrm{D}$ vitamini formu vardır: ergokalsiferol (D2) ve kolekalsiferol (D3) olmak üzere. D3 vitamini, UVB ışınımı altında sentezlenebilir veya bağırsak yoluyla somon balığ ve takviye edilmiş gıdalardan veya kolekalsiferol içeren gıda takviyelerinden elde edilebilir (2). D vitamini eksikliği dünyadaki nüfusun neredeyse $\% 50$ 'sini etkilemektedir (3). İnsan vücudunda $\mathrm{D}$ vitamini durumu 25 -hidroksi vitamin D düzeyi ile değerlendirilmektedir (4).

Fetal gelişim için ve gebelikteki preterm eylem, preeklampsi gibi komplikasyonlar için de D vitamininin önemli olduğu literatürdeki yayınlarda mevcuttur (5-10). Bunun yanında D Vitamini eksikliğinin, pankreas beta hücrelerinde insülin salınımını azalttığı ve insülin direncine katkıda bulunarak erişkin dönem diyabet patogenezinde rol oynadığı literatürde bildirilmektedir (11-13). Gestasyonel diyabet (GDM) ilk olarak gebelikte ortaya çıkan ya da gebelik sırasında tanı konulan glukoz tolerans bozukluğudur (14). Yine gebelerde de yani GDM'de D Vitamini eksikliğinin insülin direncini artırarak etki edebileceği ve hiperinsülinizme de yol açabileceği, bu konu ile ilgili az sayıda çalışma da mevcuttur (15-19).

$\mathrm{Bu}$ çalışmanın amacı Batı Karadeniz Bölgesindeki OGTT uygulanmış gebelerde, GDM saptanan ve saptanmayan gruplar arasında ilk trimester plazma D vitamini seviyesinin ilişkisini araştırmaktır.

\section{GEREÇ ve YÖNTEMLER}

Zonguldak Bülent Ecevit Üniversitesi Tip Fakültesi Klinik Araştırmalar Etik Kurulu'ndan onay alındıktan sonra 17.09.2014-15.01.2018 tarihleri arasinda Bartın Devlet Hastanesi ve Zonguldak Bülent Ecevit Üniversitesi Tip Fakültesi Kadın Hastalıkları ve Doğum Anabilim Dalına başvuran 18-40 yaş arası, tekil gebeliği olan ve ilk trimesterde maternal plazmada D vitamini seviyesi bakılmış 136 gebe çalışmaya dahil edildi, retrospektif olarak veriler tarandi. Çoğul gebelikler, gebelik öncesi diyabet gibi ek sistemik hastalığ bulunan, glukoz tarama testi yaptırmak istemeyen, ilk trimesterde D vitamini seviyesine bakılmamış ya da kan verme zamanında $\mathrm{D}$ vitamini takviyesi alan, zararlı madde kullanımı olan, çoğul gebeliği olan gebeler çalışmaya dahil edilmedi. GDM tanısı almış 52 gebe GDM grubu, diğer 84 gebe kontrol grubu olarak yaş, gravide, parite, hemoglobin değeri ve vücut kütle indeksi (VKİ) eşleşecek şekilde oluşturuldu.

Tüm katılımcılardan ayrıntılı bilgilendirilmiş onam alındı. Uluslararası Diyabet ve Gebelik Çalışma Grupları Birliği (IADPSG) önerisine göre 75 gr oral glukoz yükleme öncesi açlık glukoz $\geq 92 \mathrm{mg} / \mathrm{dl}$, yükleme sonrası 1 . saat kan glukoz $\geq 180 \mathrm{mg} /$ dl ya da 2 . saat kan glukoz $\geq 153 \mathrm{mg} /$ dl değerlerinden birinin varlığı halinde GDM tanısı konuldu. İki basamaklı tarama uygulanan hastalarda; 50 gr glukoz tarama testi için eşik değer $140 \mathrm{mg} / \mathrm{dl}$ olarak alınmıştır. Tarama testi $200 \mathrm{mg} /$ dl üzerinde saptanan olgulara 100 gr oral glukoz tolerans testi (OGTT) yapılmadan GDM tanısı konulmuştur. 50 gr glukoz tarama testi $140-200 \mathrm{mg} / \mathrm{dl}$ aralığında olanlara $100 \mathrm{gr}$ OGTT uygulanmıştır. 100 gr OGTT için NDDG kriterleri (glukoz yükleme öncesi açlık glukoz $\geq 105 \mathrm{mg} / \mathrm{dl}$, yükleme sonrası 1. saat kan glukoz $\geq 190 \mathrm{mg} / \mathrm{dl}$, 2. saat kan glukoz $\geq 165 \mathrm{mg} / \mathrm{dl}$, 3. saat kan glukoz $\geq 145 \mathrm{mg} / \mathrm{dl}$ ) kullanılmıştır. Bu test sonucunda ise en az 2 değer yüksek olduğunda GDM tanısı konulmuştur.

Çalışmanın istatistikleri SPSS 19.0 paket programında yapıldı. Sürekli değişkenlerin normal dağılıma uygunluğu Shapiro Wilk testi ile değerlendirildi $(p<0,05)$ olduğundan normal dağılım göstermeyen nicel değişkenlerin iki grup arası karşılaştırmalarında Mann Whitney U testi (nonparametrik test) kullanılmıştır.

\section{BULGULAR}

GDM saptanan 52 hasta ve GDM saptanmayan 84 hastanın; temel karakteristikleri ve $\mathrm{D}$ vitamini değerleri, tanımlayıcı analizleri ve p değerleri Tablo 1'de gösterilmiştir. İki grup yukarıda da belirtildiği gibi eşleştirildiğinden; yaş, gravida, parite, hemoglobin, VKİ değerleri açısından benzerdi $(p>0,05)$. D vitamini seviyelerine bakıldığında ise GDM saptanan grupta, ilk trimesterdeki maternal D vitamini seviyesinin GDM saptanmayan gruba göre anlamlı olarak düşük olduğu saptanmıștır ( $\mathrm{p}=0,031)$. 
Tablo 1: GDM saptanan ve saptanmayan grupların tanımlayıcı analizleri.

\begin{tabular}{|c|c|c|c|c|c|}
\hline & GDM & $\mathbf{n}$ & Ortalama $\pm S^{a}$ & Medyan (Min-Maks) & $\mathbf{p}$ \\
\hline \multirow[t]{3}{*}{ D vitamini } & + & 52 & $12,43 \pm 5,13$ & $11,80(5,10-29,00)$ & 0,031 \\
\hline & - & 84 & $14,33 \pm 4,37$ & $13,10(7,40-27,46)$ & \\
\hline & Toplam & 136 & $13,61 \pm 4,75$ & $12,00(5,10-29)$ & \\
\hline \multirow[t]{3}{*}{ Yaş } & + & 52 & $30 \pm 5,89$ & $31(18-39)$ & 0,380 \\
\hline & - & 84 & $29,37 \pm 4,81$ & $30(19-41)$ & \\
\hline & Toplam & 136 & $29,61 \pm 5,24$ & $30,00(18-41)$ & \\
\hline \multirow[t]{3}{*}{ VKİ } & + & 52 & $29,44 \pm 3,13$ & $30,15(21,00-36,85)$ & 0,421 \\
\hline & - & 84 & $29,09 \pm 3,55$ & $29,20(20,96-37,40)$ & \\
\hline & Toplam & 136 & $29,22 \pm 3,39$ & $29,84(20,96-37,40)$ & \\
\hline \multirow[t]{3}{*}{ Gravide } & + & 52 & $2,73 \pm 1,23$ & $3(1-5)$ & 0,181 \\
\hline & - & 84 & $2,48 \pm 1,04$ & $2(1-5)$ & \\
\hline & Toplam & 136 & $2,57 \pm 1,12$ & $2(1-5)$ & \\
\hline \multirow[t]{3}{*}{ Parite } & + & 52 & $1,38 \pm 1,01$ & $1(0-3)$ & 0,433 \\
\hline & - & 84 & $1,27 \pm 0,88$ & $1(0-4)$ & \\
\hline & Toplam & 136 & $1,32 \pm 0,93$ & $1(0-4)$ & \\
\hline \multirow[t]{3}{*}{$\mathrm{Hb}(\mathrm{g} / \mathrm{dL})$} & + & 52 & $11,51 \pm 1,22$ & $11,80(8,70-13,70)$ & 0,393 \\
\hline & - & 84 & $11,73 \pm 1,14$ & $12(9,00-14,20)$ & \\
\hline & Toplam & 136 & $11,65 \pm 1,17$ & $11,90(8,70-14,20)$ & \\
\hline
\end{tabular}

aSS: Standart Sapma

\section{TARTIŞMA}

Diyabet, gebelikte en sık görülen medikal komplikasyondur (20). GDM, Amerikan Diyabet Birliği’ne (ADA) göre gebelik sırasında başlamış veya ilk defa gebelikte fark edilmiş değişik derecelerdeki karbonhidrat intoleransı olarak tanımlanmaktadır (21). Türkiye'de GDM prevalansı çeşitli bölgelerde yapılan son yıllara ait çalışmalara göre \%627,9 arasında değişmektedir (22-27). Maternal hiperglisemi, özellikle gebeliğin ikinci yarısında aşırı somatik büyümenin uyarılmasına yol açan fetal hiperinsülinemiye neden olur (20). Sonuç doğum ağırlı̆̆ $>4500$ g olan makrozomidir. Ancak bununla da kalmayarak doğum sonrası bebekte ani gelişen hipoglisemi atakları ve preeklampsi, omuz takılması, düşük APGAR skoru gibi komplikasyonlar da diğer bir zararlı etkisi olmasına rağmen $(28,29)$, yine de toplumda ve hatta sağlık çalışanlarında dahi glukoz tarama testleri hakkında yeterince doğru bilgi sahibi olunmadığ son zamanlarda göze çarpmaktadır (30). Bu konuda da yeterli bilgilendirme yapılıp halkın ve hatta sağlık çalışanlarının da aydınlatılması gerekmektedir.

Bunun yanında, D vitamini eksikliği de önemli bir halk sağlığı sorunudur ve $\mathrm{D}$ vitamini alımı bu sebeple de sağlık bakanlıkları tarafınca dünya genelinde ve ülkemizde de desteklenmektedir. Literatüre göre gebelerde \%7-98'inde D vitamini eksikliği olduğu tahmin edilmektedir (31).
D vitamini GDM’nin başlangıcı için önem arz eden; hepatik metabolizmayı, pankreatik adacıkların işlevini ve gelişimini, kan kalsiyum seviyesini, oksidatif stresi, bağışıklık sistemini düzenleyebilir (32-34). Bu etkileriyle de GDM açısından da önem arz eden bir vitamindir. Bunun yanında elbette $\mathrm{D}$ vitamini eksikliğinin preeklampsi gelişiminde, preterm eylem riskinde rol aldığı da yukarıda anlatıldığ́ üzere bilinmektedir. Çeşitli çalışmalar, D vitamini eksikliği olan gebe kadınlarda preeklampsi $(6,35)$, gestasyonel diyabet $(36$, 37), erken doğum $(5,38)$ ve intrauterin büyüme kısitlaması (39) prevalansının arttı̆̆ını göstermiştir (40). Tüm bunları ele aldığımızda $\mathrm{D}$ vitamininin önemi gebelerde yadsınamaz. Ancak gebelik öncesinde D vitamini takviyesi almaya da ülkemizde ne yazık ki önem verilmemektedir. Gebelikte güvenli $\mathrm{D}$ vitamini dozu araştırılmıştır. Her 2 haftada bir 4000 IU / d veya 50000 IU dozu, serum 25-hidroksivitamin D seviyelerini $>30 \mathrm{ng} / \mathrm{mL}$ 'ye yükselterek insülin direncinde bir azalmaya yol açmıştır $(40,41)$. Bu dozaj, toksisite üretmeden gebelik komplikasyonlarındaki azalma ile ilişkilidir, ancak GDM'de D vitamini rolünü destekleyen yeterli kanıt olmadığından, Cochrane veritabanı, gebelikteki rolünü değerlendirmek için daha fazla randomize çalışmaların gerekli olduğu sonucuna varmıştır (42). Bununla birlikte D vitamini eksikliğinin antepartum düzeltilmesinin de genel beklentinin aksine GDM riskini azaltmada etkisi olmadığ verisi literatürde mevcuttur (43). 
Lacroix ve ark.nın yaptığı 655 gebeyi içeren çalışmasında ilk trimesterdeki 25-hidroksi vitamin D seviyeleri ölçülmüş, ikinci trimesterde ise kan glukoz ve insülin değerlerine bakılmıştır. IADPSG ölçütleri esas alındığında katılımcıların \%8,2'sinde GDM saptanmıştır. İlk trimesterde D vitamini seviyesi düşük çıkması GDM gelişmesi ile anlamlı olarak ilişkili bulunmuş ve D vitamini eksikliğinin GDM gelişmesinde bağımsız bir etmen olduğu yorumu yapılmıştır (44).

Zhang ve ark.nın yayımladığı metaanalize göre maternal GDM tanılı gebelerde diğer sağlıklı gebelere nazaran istatistiksel olarak anlamlı olarak düşük D vitamini seviyesi olduğu bulunmuştur ancak bölgesel farklılıklar olacağına da vurgu yapılmıştır (31). Bu metaanalize benzer şekilde literatürde sağlıklı bireylerde yapılan çalışmalarda, serum 25-hidroksi vitamin D düzeyi ile glukoz konsantrasyonu ve insülin direnci arasında ters ilişki olduğu gösterilmiştir (45). D vitamininin diyabet patogenezinde rolü olduğu ileri çalışmalarda da gösterilmiştir.

Türkiye'de bu konuda yapılmış çalışmada ise Mertoğlu ve ark. tarafınca 28 sağlıklı gebe, 15 GDM tanılı gebe ve 30 sağlıklı genç kadın üzerinde D vitamini seviyeleri üzerine yapılmış olup gruplar arasında D vitamini seviyesi açısından anlamlı fark saptanmadığı bulunmuştur (46). Ancak bu çalışmada hasta sayısının da az olduğu göz ardı edilmemelidir.

Çalışmamız bu alanda Türkiye'de yapılmış en kapsamlı çalışmadır, çift merkezli olması da ayrıca çalışmamızın güçlü bir başka yönüdür. Fakat çalışmamızın zayıf yönleri olarak retrospektif olması ve tabii Batı Karadeniz Bölgesi’ni içeren bir çalışma özelliği olmasından kaynaklı olarak tek bir coğrafik bölge içermesi sayılabilir.

Sonuç olarak literatürdeki az sayıdaki çalışmada da saptandığı gibi bizim bölgesel çalışmamızda da GDM saptanan gebelerde D vitamini eksikliği göze çarpmaktadır. Batı Karadeniz Bölgesi’ni içeren bu çalışmamız daha kapsamlı prospektif çalıșmalara yol gösterici nitelikte olacaktır. Ayrıca daha çok hastanın katılımı ile yapılacak çalışmalarda bununla birlikte ilk trimester D vitamini seviyesi ile GDM gelişim prevalansına da bakılmasını içeren diğer çalışmalara öncü bir araştırmadır.

Teșekküir

Çalışmanın istatistiksel analizi için Dr. Sibel Balcı'ya teşekkür ederiz.

\section{Etik Kurul Onayı}

Zonguldak Bülent Ecevit Üniversitesi Girișimsel olmayan klinik araştırmalar etik kurul başkanlığı: 2020/05-13 no’lu karar.

\section{Çıkar Çatışması}

Yazarlar arasında çıkar çatışması yoktur.
Finansal Destek

Araştırma için finansal destek yoktur.

Yazarların Makaleye Katkı Beyanı

Çalışma konsepti/Tasarımı: Görker Sel, Veri toplama: Görker Sel, Selen Seyhan Baydağ, Adile Yeșim Akdemir, Veri analizi ve yorumlama: Görker Sel, Aykut Barut, Müge Harma, Yazı taslağı: Görker Sel, İçeriğin eleştirel incelenmesi: Mehmet İbrahim Harma, Ülkü Özmen, Son onay ve sorumluluk: Görker Sel, Selen Seyhan Baydağ, Aykut Barut, Adile Yeşim Akdemir, Ülkü Özmen, Müge Harma, Mehmet İbrahim Harma, Süpervizyon: Mehmet İbrahim Harma, Müge Harma.

\section{KAYNAKLAR}

1. WB Grant, Wimalawansa SJ, et al. Vitamin D supplements and reasonable solar UVB should be recommended to prevent escalating incidence of chronic diseases. Br Med J. 2015;350:321.

2. Haq A, Wimalawansa SJ, et al. Clinical practice guidelines for vitamin D in the United Arab Emirates. J Steroid Biochem Mol Biol. 2018;175:4-11.

3. Holick MF. Vitamin D deficiency. N Engl J Med. 2007;357:266281.

4. Kürklü NS, Aylin AY. D Vitamini ve gestasyonel diyabet. Gümüşhane Üniversitesi Sağlık Bilimleri Dergisi. 2015;4(3):454-467.

5. Bodnar LM, Platt RW, et al. Early-pregnancy vitamin D deficiency and risk of preterm birth subtypes. Obstet Gynecol. 2015;125(2):439-447.

6. Bodnar LM, Catov JM, et al. Maternal vitamin D deficiency increases the risk of preeclampsia. J Clin Endocrinol Metab. 2007;92(9):3517-3522.

7. Baker AM, Haeri S, et al. A nested case-control study of midgestation vitamin D deficiency and risk of severe preeclampsia. J Clin Endocrinol Metab. 2010;95:5105-5109.

8. Singla R, Gurung P, et al. Relationship between preeclampsia and vitamin D deficiency: A case control study. Arch Gynecol Obstet. 2015;291(6):1247-1251.

9. Woo J, Giurgescu C, et al. Evidence of an association between vitamin D deficiency and preterm birth and preeclampsia: A critical review. J Midwifery Womens Health. 2019;64(5):613629.

10. Baca KM, Simhan HN, et al. Low maternal 25-hydroxyvitamin D concentration increases the risk of severe and mild preeclampsia. Ann Epidemiol. 2016;26(12):853-857.

11. Chen S, Villalta SA, et al. FOXO1 mediates vitamin D deficiency-induced insulin resistance in skeletal muscle. J Bone Miner Res. 2016;31(3):585-595.

12. Gulseth HL, Wium C, et al. Effects of vitamin D supplementation on insulin sensitivity and insulin secretion in subjects with type 2 diabetes and vitamin $\mathrm{D}$ deficiency: A randomized controlled trial. Diabetes Care. 2017; 40(7):872-878. 
13. Park S, Kim DS, et al. Vitamin D deficiency impairs glucosestimulated insulin secretion and increases insulin resistance by reducing PPAR- $\gamma$ expression in nonobese Type 2 diabetic rats. J Nutr Biochem. 2016;27:257-265.

14. Committee on Practice Bulletins-Obstetrics. ACOG Practice Bulletin No. 190: Gestational Diabetes Mellitus. Obstet Gynecol. 2018;131(2):e49-e64.

15. Amraei M, Mohamadpour S, et al. Effects of vitamin D deficiency on incidence risk of gestational diabetes mellitus: A systematic review and meta-analysis. Front Endocrinol (Lausanne). 2018;9:7.

16. Weinert LS, Reichelt AJ, et al. Vitamin D deficiency increases the risk of adverse neonatal outcomes in gestational diabetes. PLoS One. 2016;11(10).

17. Rajput R, Vohra S, et al. Severe $25(\mathrm{OH})$ vitamin-D deficiency: A risk factor for development of gestational diabetes mellitus. Diabetes Metab Syndr. 2019;13(2):985-987.

18. McCormack C, Leemaqz S, et al. Association between vitamin D status and hyperinsulinism. J Matern Fetal Neonatal Med. 2019;32(23):4005-4008.

19. Xia J, Song Y, et al. Vitamin D status during pregnancy and the risk of gestational diabetes mellitus: A longitudinal study in a multiracial cohort. Diabetes Obes Metab. 2019;21(8):18951905.

20. Mihmanlı V, Mihmanlı M. Diabetes mellitus ve gebelik. Okmeydanı Tip Dergisi. 2015;31:17-22.

21. Seshadri R. American diabetes association gestational diabetes mellitus. Diabetes Care. 2002;25:S94-96.

22. Çelik D, Karaçam Z. Türkiye'de gestasyonel diyabetes mellitus prevalansı ve risk faktörleri: Sistematik derleme ve meta analiz. Adnan Menseres Üniversitesi 1. Sağlık Bilimleri Kongresi; 29 Haziran1 Temmuz 2017; Aydın; 2017. s.802.

23. Kaya R, Karaçam Z. Gestasyonel diyabet görülme sıklı̆̆ı ve anne-bebek sağlığı ile ilişkisi. Düzce Üniversitesi Sağlık Bilimleri Enstitüsü Dergisi. 2019;9(1):10-18.

24. Özyurt R, Aşıcıoğlu O, ve ark. İstanbul Eğitim ve Araştırma Hastanesi Kadın Hastalıkları ve Doğum Kliniği’ne başvuran gebelerde gestasyonel diyabet sıklığı. JOPP Derg. 2013;5(1):712.

25. Gürlek B, Kale İ. Rize ilinde gestasyonel diabetes mellitus prevalansı. Jinekoloji Obstetrik ve Neonatoloji Tip Dergisi. 2019;16(1):31-36.

26. Şahin ME, Madendağ İÇ. Evaluation of the prevalence of gestational diabetes mellitus in Kayseri city hospital: A cross-sectional study. Journal of Surgery and Medicine. 2019;3(10):715-717.

27. Balık G, Şahin SB, ve ark. Bir üniversite hastanesinin doğum polikliniğine başvuran gebelerde gestasyonel diabetes mellitus prevalansi. Ege Tip Dergisi. 2016;55(2):55-58.

28. Roeckner JT, Bennett S, et al. Pregnancy outcomes associated with an abnormal 50-g glucose screen during pregnancy: A systematic review and Meta-analysis. J Matern Fetal Neonatal Med. 2020:1-9.
29. Akgol S, Budak MS. Obstetric and neonatal outcomes of pregnancies with mild gestational hyperglycemia diagnosed at gestational diabetes mellitus screening. Gynecology Obstetrics \& Reproductive Medicine. 2019;25(3):138-141.

30. Demircan KD, Demircan V, ve ark. Gestasyonel diyabetes mellitus taraması: Herkes için eğitim şart. Acta Medica Nicomedia. 2020;3(1):5-9.

31. Zhang Y, Gong Y, et al. Vitamin D and gestational diabetes mellitus: A systematic review based on data free of Hawthorne effect. BJOG. 2018;125(7):784-793.

32. Nikooyeh B, Neyestani TR. Oxidative stress, type 2 diabetes and vitamin D: past, present and future. Diabetes Metab Res Rev. 2016;32: 260-267.

33. Sing LP. The potential protective action of vitamin D in hepatic insulin resistance and pancreatic islet dysfunction in type 2 diabetes mellitus. Nutrients. 2016;8:147.

34. Luong KVQ, Lan THN, et al. The role of vitamin D in protecting type 1 diabetes mellitus. Diabetes Metab Res Rev. 2005;21:33846.

35. Reeves IV, Bamji ZD, et al. Vitamin D deficiency in pregnant women of ethnic minority: A potential contributor to preeclampsia. J Perinatol. 2014;34:767-773.

36. Maghbooli Z, Hossein-Nezhad A, et al. Correlation between vitamin D3 deficiency and insulin resistance in pregnancy. Diabetes Metab Res Rev. 2008;24:27-32.

37. Zhang C, Qiu C, et al. Maternal plasma 25-hydroxyvitamin D concentrations and the risk for gestational diabetes mellitus. PLoS One. 2008;3:e3753.

38. Thota C, Menon R, et al. 1,25-Dihydroxyvitamin D deficiency is associated with preterm birth in African American and Caucasian women. Reprod Sci. 2014;21:244-250.

39. Gernand AD, Simhan HN, et al. Maternal vitamin D status and small-for-gestational-age offspring in women at high risk for preeclampsia. Obstet Gynecol. 2014;123:40-48.

40. Poomalar GK. Changing trends in management of gestational diabetes mellitus. World J Diabetes. 2015;6(2):284-95.

41. Soheilykhah S, Mojibian M, et al. The effect of different doses of vitamin D supplementation on insulin resistance during pregnancy. Gynecol Endocrinol. 2013;29(4):396-399.

42. De-Regil LM, Palacios C, et al. Vitamin D supplementation for women during pregnancy. Cochrane Database Syst Rev. 2012;2:CD008873.

43. Persad MD, Staszewski C, et al. Does antepartum vitamin D3 supplementation prevent gestational diabetes mellitus? [18R]. Obstetrics \& Gynecology. 2019;133:196S.

44. Lacroix M, Battista MC, et al. Lower vitamin D levels at first trimester are associated with higher risk of developing gestational diabetes mellitus. Acta Diabetol. 2014;51(4):609616.

45. Tai K, Need AG, et al. Vitamin D, glucose, insulin, and insulin sensitivity. Nutrition. 2008;24(3):279-285.

46. Mertoğlu C, Günay M, ve ark. Gebelikte, gestasyonel diyabette ve üreme çă̆ı kadınlarında D vitamini düzeyi. Van Tıp Dergisi. 2017;24(4): 328-332. 